\title{
Elevated MED28 expression predicts poor outcome in women with breast cancer
}

\author{
Nam K Yoon', Erin L Maresh1', Yahya Elshimali1', Ai Li², Steve Horvath2,3,4, David B Seligson'1,4, David Chia1,4 and \\ Lee Goodglick*1,4
}

\begin{abstract}
Background: MED28 (also known as EG-1 and magicin) has been implicated in transcriptional control, signal regulation, and cell proliferation. MED28 has also been associated with tumor progression in in vitro and in vivo models. Here we examined the association of MED28 expression with human breast cancer progression.

Methods: Expression of MED28 protein was determined on a population basis using a high-density tissue microarray consisting of 210 breast cancer patients. The association and validation of MED28 expression with histopathological subtypes, clinicopathological variables, and disease outcome was assessed.

Results: MED28 protein expression levels were increased in ductal carcinoma in situ and invasive ductal carcinoma of the breast compared to non-malignant glandular and ductal epithelium. Moreover, MED28 was a predictor of disease outcome in both univariate and multivariate analyses with higher expression predicting a greater risk of disease-related death.

Conclusions: We have demonstrated that MED28 expression is increased in breast cancer. In addition, although the patient size was limited (88 individuals with survival information) MED28 is a novel and strong independent prognostic indicator of survival for breast cancer.
\end{abstract}

\section{Background}

In 2008, an estimated 40,000 women died of breast cancer and over 190,000 women were newly diagnosed with the disease, making breast cancer the second leading cause of cancer death in women [1]. Although treatment based on the molecular characteristics of breast cancer subtypes has helped improve prognosis, much progress needs to be made (reviewed in [2-4]). The characterization of novel markers to augment our understanding of cancer and our ability to predict patient outcomes will greatly improve breast cancer management. A recently identified marker, MED28 (also known as EG-1 or magicin), has been found to be increased in breast cancer and may play a role in the progression of the disease [5-9].

MED28 is a 178 amino acid, $\sim 24 \mathrm{kDa}$ protein that was first identified as being differentially expressed in endothelial cells exposed to conditioned media from tumor cells $[5,6]$. Although the exact function of MED28

\footnotetext{
*Correspondence: Igoodglick@mednet.ucla.edu

1 Department of Pathology and Laboratory Medicine, David Geffen School of Medicine at UCLA, Los Angeles, California, 90095, USA

Full list of author information is available at the end of the article
}

is unknown, it has been identified as one of approximately 30 subunits within the mammalian Mediator complex, which regulates activation and repression of RNA polymerase II transcribed genes [10-13]. In addition, MED28 has been found to be a binding partner for merlin, a cytoskeleton-related tumor suppressor important in neurofibromatosis 2 development $[12,14]$.

Clues as to functional consequences of MED28 expression have been found in tumor model systems. The presence of MED28 has been shown to increase cellular proliferation in both cell culture and mouse xenograft models using human breast cancer cells [7]. Inhibition of MED28 expression by either siRNA or anti-MED28 antibody decreases cellular proliferation in vitro and in vivo [9]. Finally, in retrospective studies on human tissue samples, MED28 has been found to be up-regulated in breast, prostate, and colon cancers [6].

Here we examine the expression levels of MED28 on a population basis using a human breast cancer tissue microarray (TMA). Our findings show that MED28 expression is a significant independent predictor of survival in women with both early and late stage breast cancer. 


\section{Methods}

\section{Characteristics of the Breast TMA}

\section{Surgical cases represented on the TMA}

A high-density breast TMA was constructed and utilized as previously described [15-17] with appropriate oversight by the UCLA Institutional Review Board. Briefly, the TMA was built using cores from archived formalinfixed, paraffin-embedded breast tissue samples from 242 cases of patients who underwent surgery at the UCLA Medical Center between 1995 and 2000. Of these 242 cases, 213 women had surgery for suspected breast cancer while 29 women had breast reduction surgery. A "case" is defined as a surgery for which tissue was removed and could be used to construct the TMA. Of the women who had surgery for suspected breast cancer, 134 individuals had their primary surgery at UCLA. An additional 79 women came to the UCLA Medical center for a secondary follow-up surgery.

The spectrum of overall case histologies from the 213 patients who had surgery due to suspected cancer were as follows: 179 cases with invasive breast cancer histology (this was sub-divided into 122 cases which contained both invasive and in situ tumor histologies, and 57 cases which had invasive tumor histology alone); in situ tumor histology alone (22 cases); and individuals who had suspected cancer but who, upon surgery, were found to have ductal hyperplasia, atypical ductal hyperplasia, atypical lobular hyperplasia, or intraductal papilloma $(4,1,2$, and 5 cases respectively). Within the patients with invasive breast cancer (179 cases), 72 cases were associated with metastases. Forty-nine of these patients presented with metastasis at their first surgery (48 lymph node metastases, 1 distant metastasis).

\section{Characteristics of spots on the TMA}

At least three samples (cores) of each histology were taken to represent a given histology in each case. In total, the TMA consisted of 2,039 cores of which 924 were readable. Note that unreadable spots primarily included those that contained only stroma or fat or those that had fallen off during processing. The breakdown by core histology was 506 invasive tumors (440 invasive ductal carcinoma (IDC), 66 other breast cancer variants including invasive lobular carcinoma, invasive tubular carcinoma, apocrine carcinoma, mixed invasive ductal and lobular carcinoma, and medullary carcinoma), 98 in situ tumors (92 DCIS + 6 LCIS), 110 metastatic lesions, 14 atypical hyperplasia, 39 ductal hyperplasia, 109 normal matched tissues, 21 benign tissues, and 27 cores from breast reduction cases.

\section{Case inclusion and exclusion criteria for outcomes analyses}

Only primary surgical cases of patients who did not receive neoadjuvant therapy were used for outcome analyses. The criteria for inclusion and exclusion of cases are shown in Figure 1. Briefly, of the 134 individuals who had primary surgery for suspected breast cancer at the UCLA Medical Center, 46 cases were excluded as shown in Figure 1, leaving 88 and 66 women for which we had i) survival or ii) recurrence and survival outcome information, respectively.

\section{Immunohistochemistry}

The breast TMA was evaluated for MED28 expression using a standard immunohistochemistry protocol as previously described [6,15-17]. Briefly, $4 \mu \mathrm{m}$ thick TMA sections were cut, deparaffinized, treated for antigen retrieval with $10 \mathrm{mM}$ sodium citrate, $\mathrm{pH} 6\left(95^{\circ} \mathrm{C}\right.$ for 20 $\mathrm{min})$, quenched for endogenous peroxidase activity, and blocked with $5 \%$ horse serum before incubation for 30 minutes with anti-MED28 primary antibody at a 1:300 dilution. The primary antibody was a polyclonal rabbit anti-human-MED28 antibody produced in the laboratory of Dr. Mai Brooks [6]. The primary antibody was detected by applying a horse anti-rabbit HRP secondary antibody and an avidin-biotin complex (Vector Laboratories, Burlingame, CA) followed by diaminobenzidine. Negative controls included primary incubation with preimmune rabbit serum. Her-2/neu status was determined by immunohistochemistry using the Hercep Test guidelines (DAKO, catalog K5204, Carpinteria, CA).

\section{TMA Scoring}

Semiquantitative evaluation of MED28 staining was performed by a pathologist who tabulated the percentage of glandular cells that exhibited cytoplasmic staining at each intensity, from 0 to 3 ( 0 being below the level of detection, 1 being weak, 2 being moderate and 3 representing highest expression) as previously described [15-18]. Briefly, an integrated value was used to account for frequency and intensity of staining for each spot. The following formula was used to calculate this integrated value: $[3(\% x)+2(\% y)$ $+1(\% \mathrm{z})] / 100$, where $\mathrm{x}, \mathrm{y}$, and $\mathrm{z}$ represent the percentage of cells staining at intensity 3,2 , and 1 , respectively. Survival analyses were analyzed with patient case data. Case data was analyzed by using pooled expression results as previously described [16-19].

\section{Statistical Analyses}

Individual integrated intensity measures for each spot were used for spot-level analysis, while the mean integrated intensity values for each case were used for caselevel analysis as previously described [16-20]. Non-parametric two-group and multi-group comparisons were performed using the Mann-Whitney and Kruskal-Wallis tests, respectively. Non-parametric correlative analyses were performed using the Spearman correlation. Evaluation of MED28 and other clinico-pathological variables was performed using a Cox proportional hazards model. Patients were dichotomized at the $75^{\text {th }}$ percentile of MED28 expression for the whole cohort (defined high 


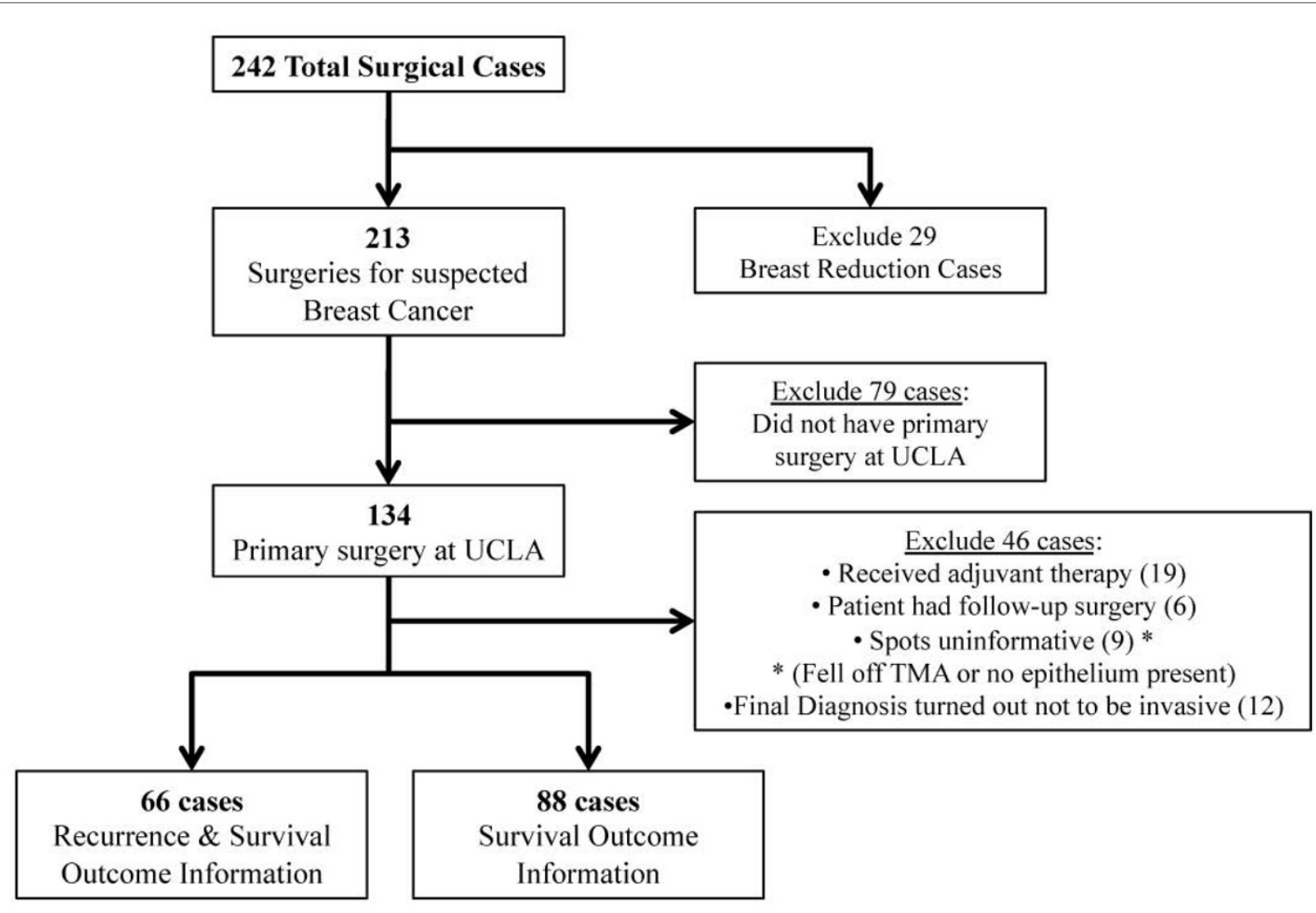

Figure 1 Inclusion and exclusion criteria for outcome analyses. The flow chart shows which cases were included in recurrence and survival analyses.

and low expression is shown in Table 1). Survival was visualized via Kaplan-Meier curves, and survival differences were tested using the log-rank test [16-20]. The statistical independence and significance of MED28 along with covariates were evaluated in a multivariate Cox model. All statistical analyses were performed using StatView Version 5.0 (SAS Institute, Cary, NC) or with the freely available software package, $\mathrm{R}$ http://www.r-project.org.

\section{Results}

MED28 levels are elevated in breast cancer

Previously, expression of MED28 was found to promote proliferation in breast cancer cells [7]. Based on this, we predicted that MED28 expression levels could yield clinically relevant information about breast cancer development and/or progression. To start testing this, we examined the expression of MED28 in a population of women with breast cancer using high-throughput TMA technology. The TMA consisted of 242 surgical cases from patients seen at the UCLA Medical Center between 1995 and 2000. Table 1 shows the clinical and demographic characteristics of the patient population utilized for outcomes analyses. Consistent with previous results,
MED28 expression could be observed in both the cytoplasm and nucleus of cells (Figure 2A, B, C, D, E, and 2F). The expression pattern in the nuclear and cytoplasmic components was highly correlated, therefore analyses of cytoplasmic expression are shown here, and analogous results examining nuclear staining can be found in the Additional Files (Additional File 1 and Additional File 2).

We first examined the expression level of cytoplasmic MED28 for each histology or histopathology. We observed low expression of MED28 in morphologically normal and hyperplastic (DH) breast epithelium (Figure 3). In contrast, MED28 expression in DCIS and invasive ductal carcinoma lesions was approximately three-fold higher than either normal or DH levels $(\mathrm{P}<0.0001$; Figure 3). This confirms and validates previous findings showing enhanced expression of MED28 in breast cancer [6]. Similarly, malignant cells which had metastasized to the lymph nodes expressed $>3$ fold higher levels of MED28 than normal epithelium $(\mathrm{P}<0.0001$; Figure 3$)$.

\section{Relatively high levels of MED28 predict a greater likelihood} of tumor recurrence

We next examined whether MED28 expression yielded relevant information regarding disease outcome. First, we 
Table 1: Clinico-pathologic characteristics and MED28 expression in individuals with breast cancer

\begin{tabular}{|c|c|c|c|c|c|c|}
\hline \multirow[b]{3}{*}{ All Invasive Patients } & \multirow[b]{3}{*}{$\mathbf{N}=\mathbf{8 8}$} & \multicolumn{2}{|c|}{ MED28 Expression } & \multicolumn{2}{|c|}{ Dichotomized } & \multirow{3}{*}{$\begin{array}{l}\text { Continuous } \\
\text { P-Value }\end{array}$} \\
\hline & & & High & P-Value & $\overline{\mathrm{x}} \pm \sigma$ & \\
\hline & & $N=66$ & $N=22$ & & $0.946 \pm 0.668$ & \\
\hline Age at Diagnosis & & $\overline{\mathrm{x}}=55.2$ & $\overline{\mathrm{X}}=55.9$ & $0.8926^{a}$ & $\rho=0.024 b$ & $0.8195^{b}$ \\
\hline Median (Range) & $53(30-89)$ & $53.5(30-89)$ & $52(36-89)$ & & & \\
\hline $\begin{array}{l}\text { 25th to 75th } \\
\text { Quartile }\end{array}$ & $45-66$ & $45-74$ & $45-77.2$ & & & \\
\hline Clinical Stage & & $\overline{\mathrm{x}}=1.712$ & $\bar{x}=2.318$ & $0.0035^{a}$ & & $0.0052^{b}$ \\
\hline 1 & 33 & 28 & 5 & $0.0028^{d}$ & $0.782 \pm 0.721$ & $0.0090^{e}$ \\
\hline ॥ & 36 & 30 & 6 & & $0.918 \pm 0.541$ & \\
\hline III & 17 & 7 & 10 & & $1.312 \pm 0.708$ & \\
\hline IV & 2 & 1 & 1 & & $1.075 \pm 0.813$ & \\
\hline Tumor Grade & & $\overline{\mathrm{x}}=2.063$ & $\overline{\mathrm{X}}=2.455$ & $0.0678^{a}$ & & $0.0061^{b}$ \\
\hline 1 & 23 & 21 & 2 & $0.0882^{d}$ & $0.598 \pm 0.429$ & $0.0099^{f}$ \\
\hline 2 & 25 & 17 & 8 & & $1.009 \pm 0.698$ & \\
\hline 3 & 37 & 25 & 12 & & $1.112 \pm 0.726$ & \\
\hline Unknown & 3 & 3 & 0 & & & \\
\hline $\begin{array}{l}\text { Lymph Node } \\
\text { Metastasis }\end{array}$ & & & & $0.1004 c$ & & $0.0303^{a}$ \\
\hline Absent & 38 & 32 & 6 & & $0.833 \pm 0.775$ & \\
\hline Present & 34 & 22 & 12 & & $1.083 \pm 0.612$ & \\
\hline Unknown ${ }^{\dagger}$ & 16 & 12 & 4 & & & \\
\hline Tumor Size (cm) & & $\overline{\mathrm{x}}=2.175$ & $\overline{\mathrm{x}}=2.955$ & $0.0283^{a}$ & $\rho=0.303^{b}$ & $0.0060^{b}$ \\
\hline Median (Range) & $2.2(0.1-9.0)$ & $2.0(0.1-7.25)$ & $2.5(0.5-9.0)$ & & & \\
\hline $\begin{array}{l}\text { 25th to 75th } \\
\text { Quartile }\end{array}$ & $1.18-3.00$ & $1.0-2.5$ & $1.7-4.0$ & & & \\
\hline $\begin{array}{l}\text { Lymphovascular } \\
\text { Invasion }\end{array}$ & & & & $0.0720^{c}$ & & $0.0201^{a}$ \\
\hline Absent & 55 & 45 & 10 & & $0.812 \pm 0.599$ & \\
\hline Present & 32 & 20 & 12 & & $1.177 \pm 0.734$ & \\
\hline Unknown & 1 & 1 & 0 & & & \\
\hline ER Status & & & & $0.2514^{c}$ & & $0.0489^{a}$ \\
\hline Positive & 62 & 48 & 14 & & $0.866 \pm 0.594$ & \\
\hline Negative & 21 & 13 & 8 & & $1.271 \pm 0.822$ & \\
\hline Unknown & 5 & 5 & 0 & & & \\
\hline PR Status & & & & $0.0640^{c}$ & & $0.1828^{a}$ \\
\hline Positive & 58 & 47 & 11 & & $0.864 \pm 0.562$ & \\
\hline Negative & 28 & 17 & 11 & & $1.142 \pm 0.838$ & \\
\hline Unknown & 2 & 2 & 0 & & & \\
\hline HER-2/neu Status & & & & $0.0335^{c}$ & & $0.1022^{a}$ \\
\hline Positive & 19 & 10 & 9 & & $1.181 \pm 0.644$ & \\
\hline Negative & 61 & 49 & 12 & & $0.923 \pm 0.661$ & \\
\hline Unknown & 8 & 7 & 1 & & & \\
\hline
\end{tabular}

(a) Mann-Whitney, (b) Spearman Correlation, (c) Fisher's Exact Test, (d) Chi-Square Test, (e) Mann-Whitney with clinical stage dichotomized as stage I\&II vs. III\&IV, and (f) Kruskal-Wallis Test. Cases that were uninformative for a given variable were removed from statistical analysis. ${ }^{\mathrm{N}} \mathrm{No}$ lymphadenectomies were performed for these patients. 

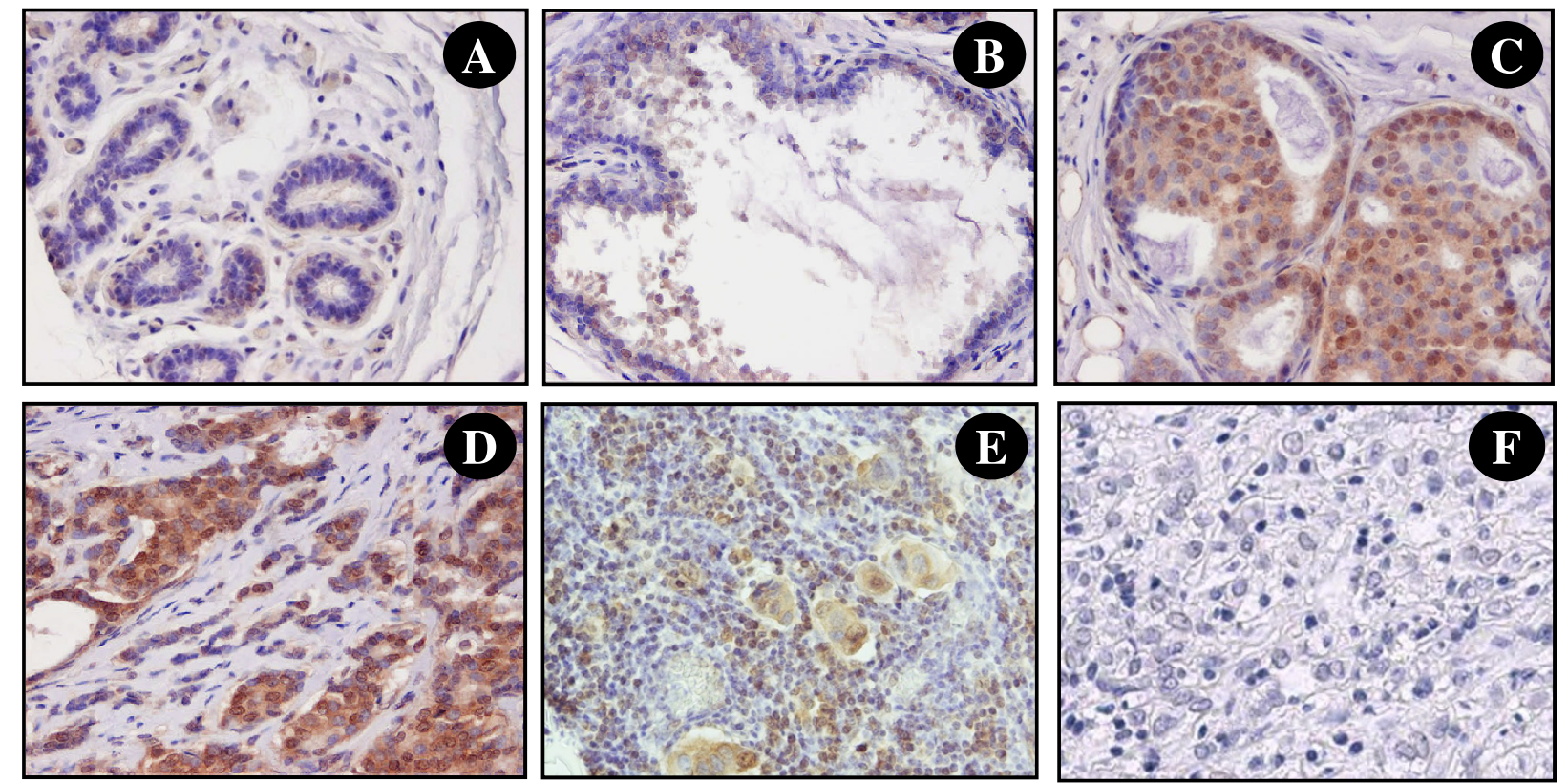

Figure 2 MED28 expression in breast tissue samples. By immunohistochemical staining, MED28 is observed in the cytoplasm and nucleus of epithelial cells. Shown is representative staining of $\mathbf{A}$ ) morphologically normal tissue; B) ductal hyperplasia (DH); C) ductal carcinoma in situ (DCIS), D) invasive ductal carcinoma (IDC), E) lymph node metastases; and F) IDC negative control with non-immune primary antibody. In all experiments, substitution of primary antibody with a species matched non-immune reagent showed no staining.

considered tumor recurrence. In a univariate Cox model, MED28 as a continuous variable was not a significant predictor of tumor recurrence $(\mathrm{P}=0.113)$; however, when we dichotomized expression levels, MED28 was a significant predictor, with relatively higher levels of MED28 expression predicting a significantly greater chance of

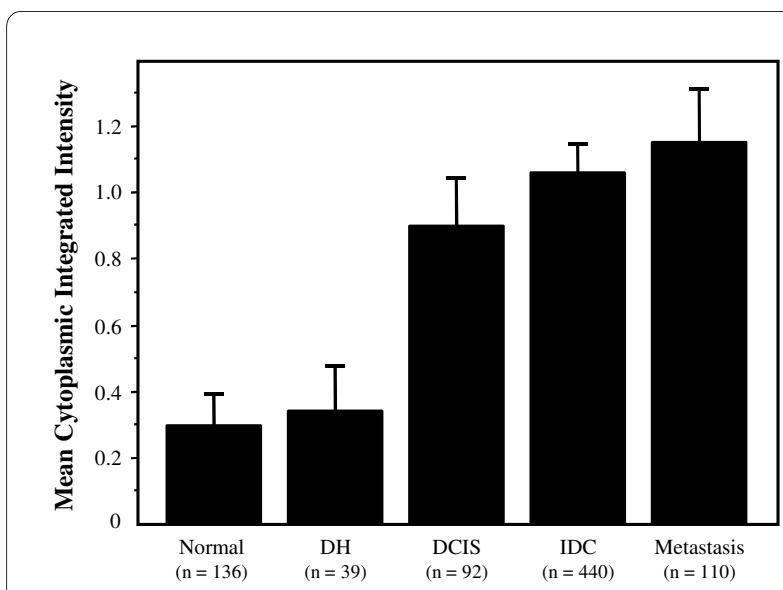

Figure 3 MED28 expression by histology. MED28 expression as classified by different TMA spot-level histologies. The columns show the mean integrated cytoplasmic expression of MED28; bars, SE. MED28 expression in DCIS, IDC, and metastatic lesions were significantly elevated compared to either normal or DH tissues $(P<0.0001)$. MED28 expression in DCIS lesions was also slightly different from expression in metastatic lesions $(P=0.040)$. $n$ is the number of spots in each category. breast cancer recurrence than those with lower MED28 expression (Figure 4A; $\mathrm{P}=0.027$ ).

\section{Relatively high levels of MED28 predict a poorer survival outcome}

We next examined whether MED28 expression profile predicted survival. Importantly, MED28 expression both as a continuous variable $(\mathrm{P}=0.011)$ and as a dichotomized variable (Table 2 ; $\mathrm{P}<0.0001$ ) was a significant predictor of disease-specific survival. As shown in Figure 4B, Kaplan-Meier analysis demonstrates that patients with relatively higher levels of MED28 had a dramatically lower probability of survival compared with individuals whose tumors expressed relatively lower levels of MED28 $(\mathrm{P}<0.0001)$. This effect was observed both at early stage (Figure 5A; $\mathrm{P}=0.037$ ) and late stage (Figure 5B; $\mathrm{P}=0.034$ ) cancers.

We further assessed any correlative association between MED28 expression and other clinico-pathological variables (Table 1). As a continuous variable, elevated MED28 was significantly associated with higher tumor grade $(P=0.006)$, lymph node metastases $(P=0.030)$, lymphovascular invasion ( $\mathrm{P}=0.024)$, and estrogen receptor $(\mathrm{ER})$ negativity $(\mathrm{P}=0.049)$. As a dichotomized variable, elevated MED28 was significantly associated with higher stage $(P=0.003)$, greater tumor size $(P=0.028)$ and HER2/neu negativity $(\mathrm{P}=0.033)$. Because of these associations, we assessed whether MED28 was an independent predictor of disease survival. To do this we used 

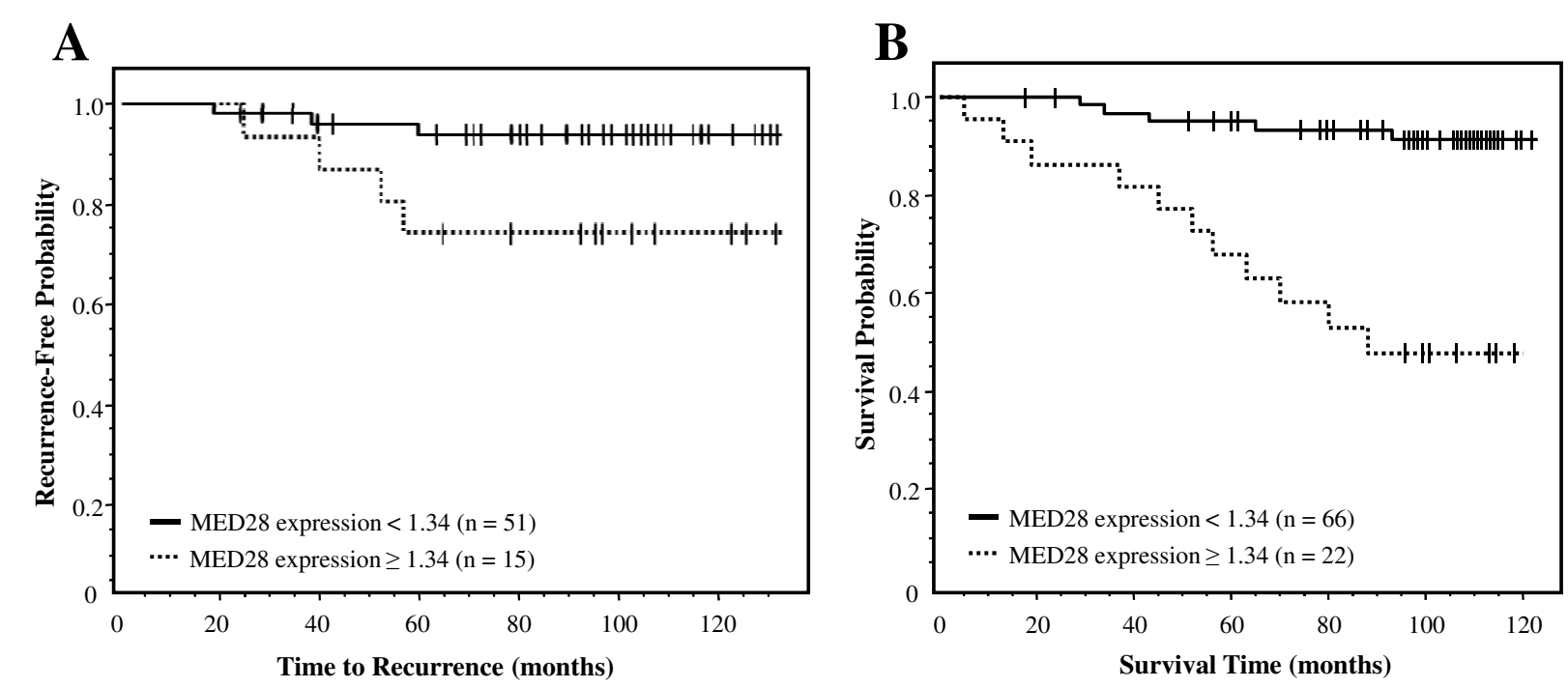

Figure 4 MED28 expression levels predict tumor recurrence and survival in women with breast cancer. Solid line is lower MED28 expression (cut-off $<1.34$, integrated cytoplasmic expression); dashed line is higher MED28 expression (cut-off $\geq 1.34$, integrated cytoplasmic expression). $\mathrm{n}$ is the number of individuals in each category. A) Higher MED28 expression predicted a greater risk of breast cancer recurrence following surgery $(P=0.027)$. B) Individuals with higher MED28 expression had an increased probability of death due to disease compared to those individuals with lower MED28 $(P<0.0001)$. In this group of individuals, 5 patients had no MED28 expression in their tumor and 83 patients had some degree of positivity.

a multivariate Cox model which included MED28 as a dichotomized variable, stage, tumor grade, age, ER expression status, and HER2/neu expression. MED28 emerged as an independent predictor of disease-specific survival $(\mathrm{HR}=5.662,95 \% \mathrm{CI}=1.178-27.21, \mathrm{P}=0.030$; Table 3); MED28 was even a stronger predictor than stage $(\mathrm{HR}=3.169,95 \% \mathrm{CI}=0.821-12.23, \mathrm{P}=0.094)$.

\section{Discussion}

In this study, we examined the expression of MED28 on a population basis using TMA technology. MED28 levels were increased in DCIS lesions as well as invasive breast cancer compared to morphologically normal breast epithelium. In addition, MED28 was up-regulated in metastatic cells in lymph nodes. These results are in agreement with previous results in which a smaller number of patient samples were examined [6]. Significantly, we further observed that MED28 was a strong predictor of disease outcome with higher levels of MED28 indicating an increased probability of death due to breast cancer in the 88 individuals examined with survival information. These results are consistent with data from in vitro and mouse model systems in which up-regulation of MED28 enhanced cell proliferation and tumor growth [7]. Inhibi-

Table 2: Univariate Cox Model Regression Analysis

\begin{tabular}{llll}
\hline Variable & Hazard Ratio & 95\% Confidence Interval & \\
& & & P-Value \\
Age at Diagnosis & 0.976 & $0.937-1.02$ & 0.250 \\
Stage (I \& II vs. III \& IV) & 5.81 & $2.16-15.7$ & 0.0001 \\
Grade (I \& II vs. III) & 2.32 & $0.843-6.39$ & 0.100 \\
Lymph Node Metastasis & 5.03 & $1.4-18.1$ & 0.013 \\
Tumor Size (cm) & 1.19 & $0.926-1.52$ & 0.180 \\
Lymphovascular Invasion & 3.04 & $0.951-9.7$ & 0.061 \\
ER Status & 0.541 & $0.196-1.49$ & 0.230 \\
PR Status & 0.562 & $0.209-1.51$ & 0.250 \\
HER-2/neu Status & 3.71 & $1.25-11.1$ & 0.018 \\
MED28 expression & 2.09 & $1.18-3.7$ & 0.011 \\
\hline
\end{tabular}



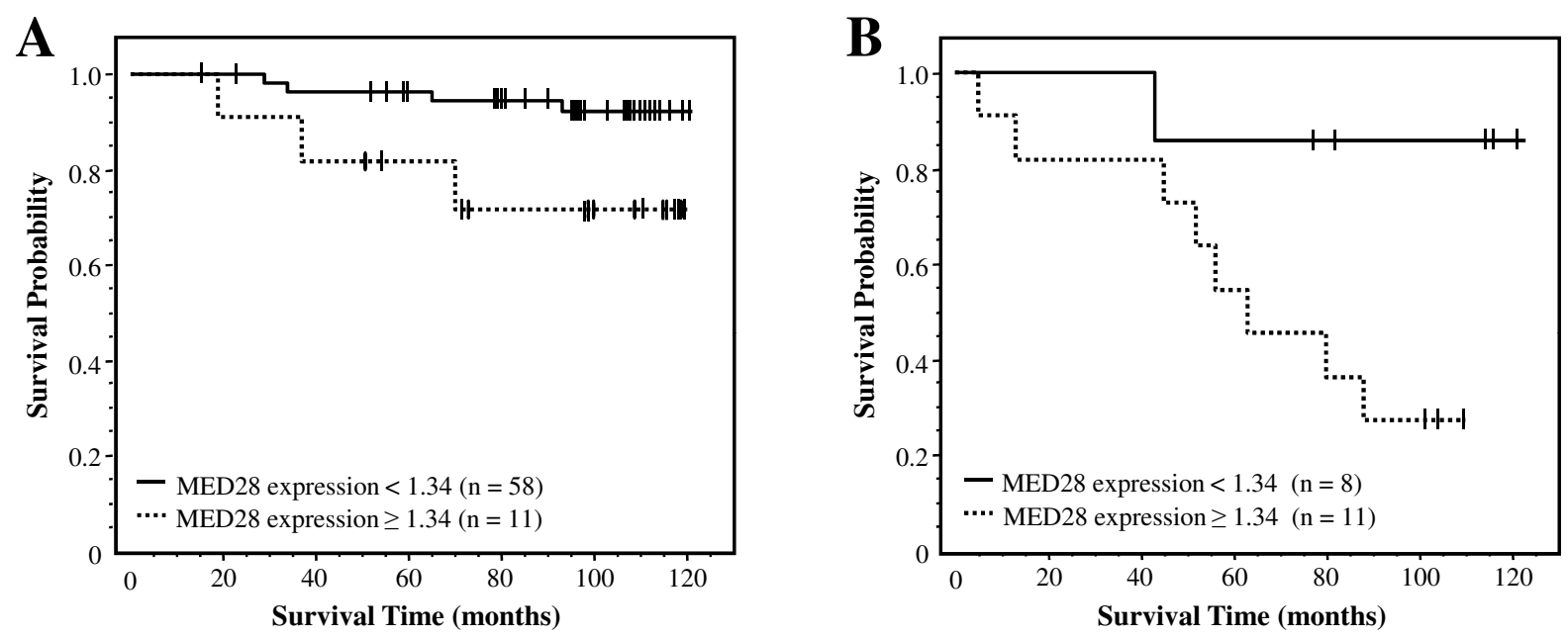

Figure 5 MED28 levels predict survival likelihood in women with low stage or high stage breast cancer. Solid line is lower MED28 expression (cut-off $<1.34$, integrated cytoplasmic expression); dashed line is higher MED28 expression (cut-off $\geq 1.34$, integrated cytoplasmic expression). $n$ is the number of individuals in each category. A) In women with low stage breast cancer (stage I/II), higher MED28 expression predicted a greater risk of death due to disease compared to those individuals with lower MED28 ( $\mathrm{P}=0.037)$. B) In women with high stage breast cancer (stage III/IV), higher MED28 expression predicted a greater risk of death due to disease compared to those individuals with lower MED28 $(P=0.034)$.

tion of MED28 by antibody or siRNA blocked these effects [9].

The cellular function of MED28 is currently being elucidated. Although MED28 was initially discovered as a differentially expressed gene in human endothelial cells treated with conditioned media from human cancers [5], it was also characterized as a binding partner for the actin-associated neurofibromatosis 2 (NF2) tumor suppressor merlin as well as the adaptor protein Grb2 [12]. These and other results are consistent with MED28 functionally linking membrane receptor signaling to cytoskeletal changes. MED28 has further been shown to bind the $\mathrm{SH} 3$ domain of src-family members suggesting that one mode of operation is through interaction with kinase signaling molecules Src, Lck, and/or Fyn [11]. Interestingly, over-expression of MED28 in vitro has been shown to activate c-Src and stimulate the c-Src signaling pathway [8]. Src activation can contribute to the malignant pheno- type through enhancing processes such as proliferation, invasion, migration, and metastasis (reviewed in [21-24]).

Interestingly, MED28 has been observed both in the cytoplasm and the nucleus as described by us and others $[6,10,13]$. Consistent with this, MED28 is one of the subunits of the highly conserved mammalian mediator complex. This complex functions as a co-activator required for the induction of transcription by RNA polymerase II [25-30]. It has been suggested that MED28 translocates between the nucleus and cytoplasm and therefore may potentially function in transducing membrane-derived signals into gene expression events.

\section{Conclusions}

The present study shows that the expression of MED28 is relatively higher in both early and advanced breast cancer lesions. Such elevated levels predict a poorer survival. That MED28 expression was elevated in DCIS lesions

Table 3: Multivariate Cox proportional hazards analysis

\begin{tabular}{llll}
\hline Variable & Hazard Ratio & $\mathbf{9 5 \%}$ Confidence Interval & P-Value \\
\hline MED28 Dichotomized & 5.662 & $1.178-27.21$ & 0.030 \\
Stage (I \& II vs. III \& IV) & 3.169 & $0.821-12.23$ & 0.094 \\
Grade (I \& II vs. III) & 1.808 & $0.698-4.68$ & 0.220 \\
Age at Diagnosis & 0.956 & $0.895-1.02$ & 0.180 \\
ER Status & 0.832 & $0.241-2.87$ & 0.770 \\
HER-2/neu Status & 1.346 & $0.399-4.54$ & 0.630 \\
\hline
\end{tabular}


compared to normal and was predictive in early as well as late stage patients suggests that alterations in the MED28 signaling axis may be an early indicator of disease progression and a potential therapeutic target. In addition to its potential usefulness as a prognostic factor, MED28 may eventually prove useful for targeted therapy: a recent study showed that inhibition of MED28 resulted in smaller breast tumor xenografts in mice [9].

\section{Additional material}

Additional file 1 Correlation of Nuclear and Cytoplasmic Expression

of MED28. MED28 expression was observed in both the cytoplasm and the nucleus in most breast tissues examined. To assess correlation, integrated intensity measures for each spot were compared for nuclear versus cytoplasmic expression. As shown in File 1S, there is a high degree of correlation between the expression pattern in the nuclear and cytoplasmic components.

Additional file 2 Nuclear Expression of MED28 is Predictive of Survival in Breast Cancer Patients. Similar to our analyses using cytoplasmic MED28 expression levels, we also examined whether the level of nuclear MED28 expression predicted survival outcome in women with breast cancer. Case expression levels were pooled as previously described [16-19], and patient integrated MED28 expression levels were dichotomized into high versus low MED28 levels using an optimized cut-point. Survival was visualized via Kaplan-Meier curves, and survival differences were tested using the log-rank test as described in this manuscript and as previously outlined [1620]. Similar to results based on cytoplasmic expression, higher levels of nuclear MED28 predicted a much poorer survival (File 2S; $\mathrm{P}=0.0047$ )

\section{Abbreviations}

TMA: Tissue Microarray; DH: ductal hyperplasia, DCIS: ductal carcinoma in situ, ER: estrogen receptor; PR: progesterone receptor, EG-1: endothelial-derived gene-1; HR: hazard ratio; Cl: confidence interval; NF2: neurofibromatosis 2.

\section{Competing interests}

The authors declare that they have no competing interests.

\section{Authors' contributions}

NKY: performed experimentation, statistical analyses and data interpretation. ELM: aided in statistical analyses and data interpretation and drafted the manuscript. YE: performed scoring of the tissue array. AL and SH: provided expertise in statistical analysis. DBS and DC: aided in project strategy and study planning. LG: aided in data interpretation and project strategy, planning, and design and critically revised the manuscript. All authors have read and approved the final manuscript.

\section{Acknowledgements}

We would like to thank Mai N. Brooks for helpful discussion and for anti-MED28 antibody reagents. We would also like to thank Stephanie Hanna and Greg Kanter for excellent technical assistance and Jacob Schatz for stimulating discussion. This work was supported in part by the Early Detection Research Network NCl CA-86366 (LG, DC) and the Jonsson Comprehensive Cancer Center (JCCC) Shared Resource Core Grant at UCLA NIH NCl 2 P30 CA16042-29 (DS).

\section{Author Details}

'Department of Pathology and Laboratory Medicine, David Geffen School of Medicine at UCLA, Los Angeles, California, 90095, USA, 2Department of Biostatistics, David Geffen School of Medicine at UCLA, Los Angeles, California, 90095, USA, ${ }^{3}$ Department of Human Genetics, David Geffen School of Medicine at UCLA, Los Angeles, California, 90095, USA and ${ }^{4}$ Jonsson Comprehensive Cancer Center, David Geffen School of Medicine at UCLA, Los Angeles, California, 90095, USA

Received: 11 September 2009 Accepted: 28 June 2010 Published: 28 June 2010
References

1. Jemal A, Siegel R, Ward E, Hao Y, Xu J, Murray T, Thun MJ: Cancer statistics, 2009. CA Cancer J Clin 2009, 59(4):225-49.

2. Olopade OI, Grushko TA, Nanda R, Huo D: Advances in breast cancer: pathways to personalized medicine. Clin Cancer Res 2008, 14(24):7988-7999.

3. Sotiriou C, Pusztai L: Gene-expression signatures in breast cancer. $N$ Engl J Med 2009, 360(8):790-800.

4. Dowsett M, Dunbier AK: Emerging biomarkers and new understanding of traditional markers in personalized therapy for breast cancer. Clin Cancer Res 2008, 14(24):8019-8026

5. Liu C, Zhang L, Shao ZM, Beatty P, Sartippour M, Lane TF, Barsky SH, Livingston $E$, Nguyen M: Identification of a novel endothelial-derived gene EG-1. Biochem Biophys Res Commun 2002, 290(1):602-612.

6. Zhang L, Maul RS, Rao J, Apple S, Seligson D, Sartippour M, Rubio R, Brooks MN: Expression pattern of the novel gene EG-1 in cancer. Clin Cancer Res 2004, 10(10):3504-3508.

7. Lu M, Zhang L, Maul RS, Sartippour MR, Norris A, Whitelegge J, Rao JY, Brooks MN: The novel gene EG-1 stimulates cellular proliferation. Cancer Res 2005, 65(14):6159-6166.

8. Lu M, Zhang L, Sartippour MR, Norris AJ, Brooks MN: EG-1 interacts with c-Src and activates its signaling pathway. Int J Oncol 2006 29(4):1013-1018.

9. Lu M, Sartippour MR, Zhang L, Norris AJ, Brooks MN: Targeted inhibition of EG-1 blocks breast tumor growth. Cancer Biol Ther 2007, 6(6):

10. Beyer KS, Beauchamp RL, Lee MF, Gusella JF, Naar AM, Ramesh V: Mediator subunit MED28 (Magicin) is a repressor of smooth muscle cell differentiation. J Biol Chem 2007, 282(44):32152-32157.

11. Lee MF, Beauchamp RL, Beyer KS, Gusella JF, Ramesh V: Magicin associates with the Src-family kinases and is phosphorylated upon CD3 stimulation. Biochem Biophys Res Commun 2006, 348(3):826-831

12. Wiederhold T, Lee MF, James M, Neujahr R, Smith N, Murthy A, Hartwig J, Gusella JF, Ramesh V: Magicin, a novel cytoskeletal protein associates with the NF2 tumor suppressor merlin and Grb2. Oncogene 2004, 23(54):8815-8825.

13. Sato S, Tomomori-Sato C, Parmely TJ, Florens L, Zybailov B, Swanson SK, Banks CA, Jin J, Cai Y, Washburn MP, et al:: A set of consensus mammalian mediator subunits identified by multidimensional protein identification technology. Mol Cell 2004, 14(5):685-691.

14. Scoles DR: The merlin interacting proteins reveal multiple targets for NF2 therapy. Biochim Biophys Acta 2008, 1785(1):32-54.

15. Shen $D$, Nooraie F, Elshimali Y, Lonsberry V, He J, Bose S, Chia D, Seligson D, Chang HR, Goodglick L: Decreased expression of annexin A1 is correlated with breast cancer development and progression as determined by a tissue microarray analysis. Hum Pathol 2006, 37(12):1583-1591.

16. Seligson DB, Horvath S, McBrian MA, Mah V, Yu H, Tze S, Wang Q, Chia D, Goodglick L, Kurdistani SK: Global levels of histone modifications predict prognosis in different cancers. Am J Pathol 2009, 174(5):1619-1628.

17. Mumenthaler S, Yoon N, Li A, Mah V, Chang G, Nooraie F, Elshimali Y, Hanna S, Kim S, Horvath S, et al:: Tissue Microarrays: Construction and Utilization For Biomarker Studies. In Methods of Cancer Diagnosis, Therapy, and Prognosis Volume 1. Edited by: Hayat MA. Springer Netherlands; 2008:217-234.

18. Mah V, Seligson DB, Li A, Marquez DC, Wistuba II, Elshimali Y, Fishbein MC, Chia D, Pietras RJ, Goodglick L: Aromatase expression predicts survival in women with early-stage non small cell lung cancer. Cancer Res 2007, 67(21):10484-10490.

19. Seligson DB, Horvath S, Shi T, Yu H, Tze S, Grunstein M, Kurdistani SK: Global histone modification patterns predict risk of prostate cancer recurrence. Nature 2005, 435(7046):1262-1266.

20. Liu X, Minin V, Huang Y, Seligson DB, Horvath S: Statistical methods for analyzing tissue microarray data. J Biopharm Stat 2004, 14(3):671-685.

21. Kopetz S, Shah AN, Gallick GE: Src continues aging: current and future clinical directions. Clin Cancer Res 2007, 13(24):7232-7236.

22. Summy JM, Gallick GE: Src family kinases in tumor progression and metastasis. Cancer Metastasis Rev 2003, 22(4):337-358.

23. Martin GS: Fly Src: the Yin and Yang of tumor invasion and tumor suppression. Cancer Cell 2006, 9(1):4-6.

24. Resh MD: The ups and downs of SRC regulation: tumor suppression by Cbp. Cancer Cell 2008, 13(6):469-471. 
25. Gu W, Malik S, Ito M, Yuan CX, Fondell JD, Zhang X, Martinez E, Qin J, Roeder RG: A novel human SRB/MED-containing cofactor complex, SMCC, involved in transcription regulation. Mol Cell 1999, 3(1):97-108.

26. Ito M, Yuan CX, Malik S, Gu W, Fondell JD, Yamamura S, Fu ZY, Zhang X, Qin J, Roeder RG: Identity between TRAP and SMCC complexes indicates novel pathways for the function of nuclear receptors and diverse mammalian activators. Mol Cell 1999, 3(3):361-370.

27. Rachez C, Lemon BD, Suldan Z, Bromleigh V, Gamble M, Naar AM, Erdjument-Bromage $\mathrm{H}$, Tempst P, Freedman LP: Ligand-dependent transcription activation by nuclear receptors requires the DRIP complex. Nature 1999, 398(6730):824-828.

28. Naar AM, Beaurang PA, Zhou S, Abraham S, Solomon W, Tjian R: Composite co-activator ARC mediates chromatin-directed transcriptional activation. Nature 1999, 398(6730):828-832.

29. Ryu S, Zhou S, Ladurner AG, Tjian R: The transcriptional cofactor complex CRSP is required for activity of the enhancer-binding protein $\mathrm{Sp} 1$. Nature 1999, 397(6718):446-450.

30. Jiang YW, Veschambre P, Erdjument-Bromage H, Tempst P, Conaway JW Conaway RC, Kornberg RD: Mammalian mediator of transcriptional regulation and its possible role as an end-point of signal transduction pathways. Proc Natl Acad Sci USA 1998, 95(15):8538-8543.

\section{Pre-publication history}

The pre-publication history for this paper can be accessed here: http://www.biomedcentral.com/1471-2407/10/335/prepub

doi: $10.1186 / 1471-2407-10-335$

Cite this article as: Yoon et al., Elevated MED28 expression predicts poor outcome in women with breast cancer BMC Cancer 2010, 10:335

Submit your next manuscript to BioMed Central and take full advantage of:

- Convenient online submission

- Thorough peer review

- No space constraints or color figure charges

- Immediate publication on acceptance

- Inclusion in PubMed, CAS, Scopus and Google Scholar

- Research which is freely available for redistribution

Submit your manuscript at www.biomedcentral.com/submit
Ciomed Central 